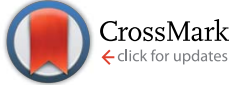

Cite this: RSC Adv., 2014, 4, 33013

\title{
Electrosprayed poly(vinylidene fluoride) microparticles for tissue engineering applications
}

\author{
D. M. Correia, ${ }^{\text {ab }}$ R. Gonçalves, ${ }^{\text {ab }}$ C. Ribeiro, ${ }^{\text {ac }}$ V. Sencadas, ${ }^{\text {ad }}$ G. Botelho, \\ J. L. Gomez Ribelles ${ }^{\text {ef }}$ and S. Lanceros-Méndez ${ }^{\star a c}$
}

Poly(vinylidene fluoride) (PVDF) microparticles have been produced by electrospraying as a suitable substrate for tissue engineering applications. The influence of the polymer solution concentration and processing parameters, such as electric field, flow rate and inner needle diameter, on microparticle size and distribution has been studied. Polymer concentration is the most influential parameter on PVDF microparticle formation. Higher concentrations promote the formation of fibers while dilute or semi dilute concentrations favor the formation of PVDF microparticles with average diameters ranging between $0.81 \pm 0.34$ and $5.55 \pm 2.34 \mu \mathrm{m}$. Once the formation of microparticles is achieved, no significant differences were found with the variation of other electrospray processing parameters. The electroactive $\beta$-phase content, between 63 and 74\%, and the crystalline phase content, between 45 and $55 \%$, are mainly independent of the processing parameters. Finally, MC-3T3-E1 cell adhesion on the PVDF microparticles is assessed, indicating their potential use for biomedical applications.

Received 15th May 2014

DOI: $10.1039 / c 4 r a 04581 \mathrm{e}$

www.rsc.org/advances features of the polymer substrate; ${ }^{7}$ scaffolds formed by polymer microparticulates can hold and populate more cells than the traditional 3D scaffolds. ${ }^{7}$

It has been shown that electroactive polymers, in particular piezoelectric poly(vinylidene fluoride) (PVDF), that generate an electrical signal in response to mechanical loads, can be used as a bioactive electrically responsive material as a promising approach for improving tissue engineering strategies, ${ }^{8-10}$ as electrical stimulation influences cell proliferation, differentiation and regeneration..$^{11,12}$

PVDF is a semi-crystalline polymer that is receiving increasing attention as a support for cell culture due to its strong piezoelectric properties, high mechanical strength, thermal stability, chemical resistance and high hydrophobicity properties. ${ }^{11,13-15}$ This polymer has at least four crystalline structures $(\alpha, \beta, \gamma$ and $\delta)$, being the $\beta$-phase the one with the largest piezoelectric response, which allows applications in the areas of sensors and actuators, energy generation and storage and, due to its biocompatibility, also in biomedical applications and tissue engineering. ${ }^{11,13-15}$

Electrospray is a promising technique for preparation of polymeric micro- and nanoparticles. ${ }^{16}$ This method might overcome some of the drawbacks associated with conventional microparticle-producing methods such as solvent casting, single and double emulsion, spray-drying, porous glass membrane emulsification and coacervation. ${ }^{16}$

The principles of electrospray are similar to the ones of the electrospinning process. In electrospray, polymer microparticles can be produced from a polymer solution in a conductive enough solvent. The variation of solution properties such 
as concentration, viscosity and surface tension, and processing parameters, such as flow rate, needle diameter, distance of the needle to the collector and applied voltage, promotes the formation of a continuous jet that can be broken down into droplets, resulting in microparticles of different size. ${ }^{\mathbf{1 6}}$ The advantage of electrospray is the fact that the droplet size can be controlled by adjusting solution and processing parameters. ${ }^{17}$

Natural and synthetic polymers have been processed in the form of microparticles by electrospray. ${ }^{18}$ The most common natural polymers produced by electrospray are gelatin, ${ }^{\mathbf{1 9}}$ chito$\operatorname{san}^{18,20}$ and elastin. ${ }^{18}$ Gelatin $^{19}$ and chitosan $^{20}$ microparticle aggregates have been used as a $3 \mathrm{D}$ scaffold in cartilage tissue engineering. Synthetic polymers including polylactides (PLAs), poly(lactic-co-glycolic acid) (PLGA) and polycaprolactone (PCL) have also been electrosprayed. ${ }^{18}$ Among other studies, PLGA microparticles of 4-5 $\mu \mathrm{m}$ in average diameter have been used as a drug delivery system for bone tissue regeneration. ${ }^{21}$

Despite to the interest of using electroactive microparticles for several applications, to our knowledge, there is just one report on the use of electrospray to prepare thin PVDF films composed by PVDF microparticles with diameters in the range of 61 to $250 \mathrm{~nm} .^{17}$

Thus, this work reports on the production of PVDF microparticles by electrospray. By controlling solution parameters, namely polymer concentration, a stable process has been achieved allowing to obtaining microparticles with controlled size. The suitability of the developed microparticles as a substrate for tissue engineering application was proven by cell viability studies performed with osteoblast-like MC3T3-E1 cells.

\section{Experimental}

\section{Materials}

Poly(vinylidene fluoride) (PVDF), reference Solef 1010, was acquired from Solvay. Analytical grade tetrahydrofuran (THF) and $\mathrm{N}, \mathrm{N}$-dimethyl formamide (DMF) were purchased from Panreac and Merck, respectively.

The polymer was dissolved in a DMF-THF co-solvent system with a volume ratio of 85/15 (v/v) for PVDF concentrations of 5, 7 and $10(\% \mathrm{w} / \mathrm{v})$. THF is selected by its lower boiling point, when compared to the DMF solvent. The ratio DMF-THF was chosen after a series of experimental measurements taken into account the polymer microspheres integrity and jet stability. The solutions were kept under agitation with a magnetic stirrer at room temperature until complete dissolution of the polymer.

\section{Electrospray processing}

The polymer solution was placed in a commercial plastic syringe fitted with a steel needle with inner diameter of $0.2,0.5$, 1 or $1.7 \mathrm{~mm}$, respectively. Electrospray was conducted by applying a voltage ranging from 15 to $25 \mathrm{kV}$ with a PS/FC30P04 power source from Glassman. A syringe pump (Syringepump) feed the polymer solution into the tip at a rate between 0.2 and $4 \mathrm{~mL} \mathrm{~h}{ }^{-1}$. The electrosprayed samples were collected on a grounded collecting plate placed at $20 \mathrm{~cm}$ from the needle tip.

\section{Characterization}

Microparticle morphology was analyzed using a scanning electron microscope (SEM, Quanta 650, from FEI) with an accelerating voltage of $5 \mathrm{kV}$. The samples were previously coated with a thin gold layer using a sputter coating (Polaron, model SC502). Microparticle average diameter and distribution was calculated over approximately 30 microparticles using the SEM images (10 000 and $30000 \times$ magnification) and the ImageJ software. Statistical differences were determined by ANOVA with $P$ values $<0.05$ statistically significant. Infrared measurements (FTIR) were performed at room temperature in a Bruker alpha apparatus in ATR mode from 4000 to $400 \mathrm{~cm}^{-1}$ using 24 scans at a resolution of $4 \mathrm{~cm}^{-1}$. Differential scanning calorimetry measurements (DSC) were performed in a Mettler Toledo 823e apparatus using a heating rate of $10{ }^{\circ} \mathrm{C} \min ^{-1}$ under nitrogen purge.

\section{Cell culture}

MC3T3-E1 cells (Riken cell bank, Japan) were cultivated in Dulbecco's modified Eagle's medium (DMEM) $1 \mathrm{~g} \mathrm{~L}^{-1}$ glucose (Gibco) containing 10\% Fetal Bovine Serum (FBS) (Fisher) and $1 \%$ penicillin/streptomycin $(\mathrm{P} / \mathrm{S})$ at $37^{\circ} \mathrm{C}$ in a $5 \% \mathrm{CO}_{2}$ incubator.

For cell culture, $10 \mathrm{mg}$ of microparticles obtained by electrospray $(7 \% \mathrm{w} / \mathrm{v})$ were placed in a $2 \mathrm{~mL}$ Eppendorf. For sterilization purposes, the microparticles were immersed in $70 \%$ ethanol, followed by washing with phosphate-buffered saline solution (PBS) 5 times for 10 min under constant shaking. Before cell seeding, fibronectin (FN) was adsorbed by immersing the microparticles in a FN solution of $20 \mu \mathrm{g} \mathrm{mL}$ overnight under constant shaking.

For the cell viability study, MC3T3-E1 cells (density of $1.5 \times$ $10^{5}$ cells per Eppendorf) were mixed with the microparticles up to 3 days. Cell pellets without any microparticles were used as reference (control + ) and only microparticles were used as negative control. For the quantification of cell viability, (3-(4,5dimethylthiazol-2-yl)-2,5-diphenyltetrazolium bromide) (MTT, Sigma-Aldrich) assay was carried out. MTT is used to measure the number of metabolic active cells based on the quantification of the activity of living cells via mitochondrial dehydrogenases. At each time point, the supernatant was removed and fresh medium containing MTT solution was added to each Eppendorf. After $3 \mathrm{~h}$ of incubation, the supernatant was removed and dimethyl sulfoxide (DMSO) was added to dissolve the MTT formazan crystals. Thereafter, the solution of each Eppendorf was mixed in a shaker in order to exclude the microparticles and the supernatant was used to determine the absorbance at $570 \mathrm{~nm}$. Three measurements were performed for each sample.

\section{Results and discussion}

\section{Microparticle morphology}

Effect of polymer concentration. During electrospray, several parameters related to process and solvent properties play a key role in the stability of the process. The solution should fulfill some requirements related to polymer solubility, proper values 
for the relative permittivity, surface tension, density, viscosity and conductivity. ${ }^{17}$ Additionally, some parameters such as flow rate, electric field, needle inner diameter and distance from the needle tip to collector have influence on the morphology and size of the obtained microparticles. ${ }^{16}$ These parameters need to be controlled and optimized in order to obtain microparticles of the desired diameter.

Fig. 1 shows representative SEM images of the PVDF microparticles prepared by electrospray from a 2, 5, 7 and 10 $(\% \mathrm{w} / \mathrm{v})$ solution concentration using a solvent mixture of THF and DMF. The corresponding microparticle size distribution is also shown in Fig. 1. Electrospray from low polymer concentration solution $(2 \% \mathrm{w} / \mathrm{v})$ did not result in microparticles with spherical geometry (Fig. 1a), a fact that can be ascribed to the low polymer content in the jet leading to low solution viscosity and high surface tensions of the solution. Under those conditions no polymer entanglement is achieved..$^{22}$ Further, diluted polymer concentrations solutions favors the formation of tailed microparticles (Fig. 1a) due to the lack of sufficiently strong polymer chain entanglements. ${ }^{22}$ On the other hand, spherical PVDF microparticles with different size distributions were obtained with polymer concentrations $5(\% \mathrm{w} / \mathrm{v})$ or more, as reported in ref. 23.
The spherical morphology of the PVDF microparticles is attributed to the complete solvent evaporation from the droplets before reaching the collector, complementary to the polymer diffusion during solvent evaporation. A rapid polymer diffusion ensures the achievement of solid and dense microparticles but does not necessarily lead to the spherical morphology. ${ }^{6,18}$

PVDF microparticles obtained from the dissolution of PVDF in the co-solvents of DMF-THF are compact due the low boiling point of THF that allows fast polymer crystallization from the liquid jet surface. The high boiling point and low vapor pressure of DMF hinders fast solvent evaporation and promotes a decrease of the mean microparticle size, leading to dense polymer microparticles (Fig. 1) ${ }^{18}$ Moreover, moisture present in the atmosphere when the electrospray is carried on, also contributes to the high surface roughness observed in Fig. 1. It has been shown in different polymer systems that high moisture levels present during electrospinning favors the presence of circular pores on top of the electrospun fibers, that become larger with increasing humidity until the coalescence to form large, non-uniform shaped structures. ${ }^{24,25}$

At a concentration of $7(\% \mathrm{w} / \mathrm{v})$ and more some thin fibers were detected among polymer microparticles and it was
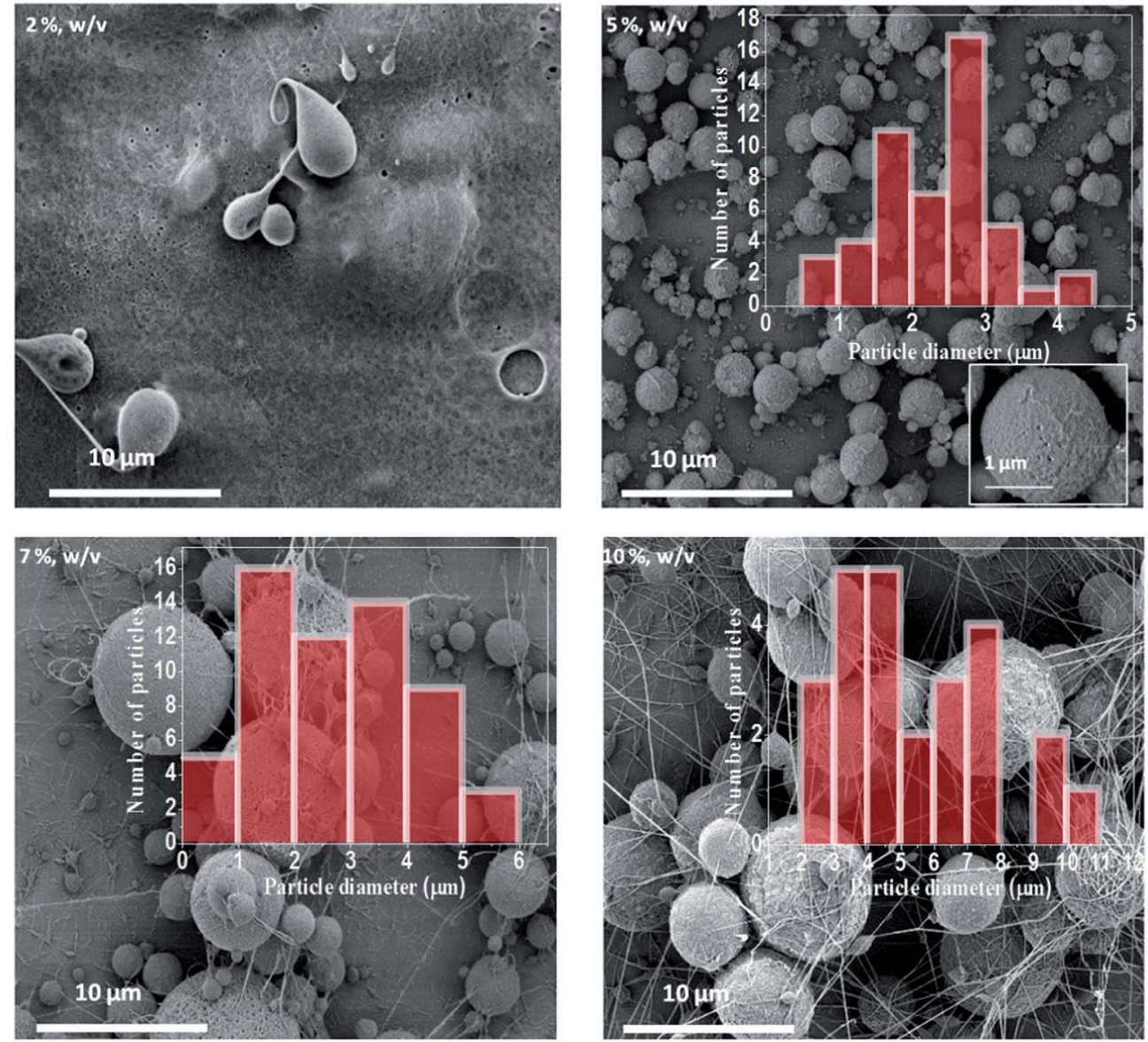

Fig. 1 Morphology of the PVDF microparticles for the samples obtained with 2 (a), 5 (b), 7 (c) and 10 (\% w/v) (d) polymer solution obtained at an applied electric field of $1 \mathrm{kV} \mathrm{cm}^{-1}$ with a needle diameter of $0.2 \mathrm{~mm}$, flow rate of $2 \mathrm{~mL} \mathrm{~h}$. The microparticle distribution obtained from each processing condition is presented as an inset. 
observed when the polymer concentration increases, the amount of fibers in the collector increases and, consequently, the amount of polymer microparticles decreases. This is related to the facts observed $i^{26}$ in which smooth and beadles PVDF fibers were obtained for polymer concentrations above 20 (\% w/ $\mathrm{v})$, leading to some beads in the fiber mats for lower polymer concentrations. Fiber formation has been also reported for polymer concentrations above $10(\% \mathrm{w} / \mathrm{v}))^{23}$ attributed to enough solution viscosity and surface tension that favors polymer chain entanglement. Our results suggest that dilute or semi-dilutes solutions favor the formation of polymer microparticles while fibers are formed for concentrated solutions above $10(\% \mathrm{w} / \mathrm{v})$ as reported in ref. 27.

In this sense, polymer concentration plays a central role in fiber or microparticle formation and therefore in process optimization. ${ }^{18}$ Thus, the ideal regime of polymer solution to obtain microparticles is the semi-dilute moderately entangled, where a significant degree of entanglement is observed and dense, solid and reproducible microparticles are obtained. ${ }^{18}$ In this state, it is essential that the concentration of the solution $(c)$ is larger than the critical entanglement concentration $\left(c_{\text {ent }}\right)$ but lower than the critical chain overlap concentration $\left(c_{\mathrm{ov}}\right)$ : for $c>3 c_{\mathrm{ov}}$ the regime is defined as semi-dilute highly entangled regime and characterized by the presence of beaded fibers or fibers. In this sense, for a PVDF concentration of $10(\% \mathrm{w} / \mathrm{v})$, the solution is in a semi-dilute highly entangled regime, ${ }^{6,18}$ being the critical entanglement concentration around $5(\% \mathrm{w} / \mathrm{v})$, in order to achieve PVDF spherical microparticles. The critical chain overlap is observed when the droplet carries enough polymer to overlap, but not sufficient to generate a significant degree of entanglement, giving origin to deformed particles and nonuniform and non-reproducible morphology. According to our results, $c_{\mathrm{ov}}$ is around $2(\% \mathrm{w} / \mathrm{v})$. The influence of polymer concentration $(5,7$ and $10(\% \mathrm{w} / \mathrm{v}))$ in the average size of the PVDF microparticles is shown in Fig. 2, resulting in an increase in the average microparticle diameter from 2.5 to $5.5 \mu \mathrm{m}$, with the increasing polymer concentration.

Effect of electric field on microparticle size. The electrospray process will be initiated when the electrostatic force in the

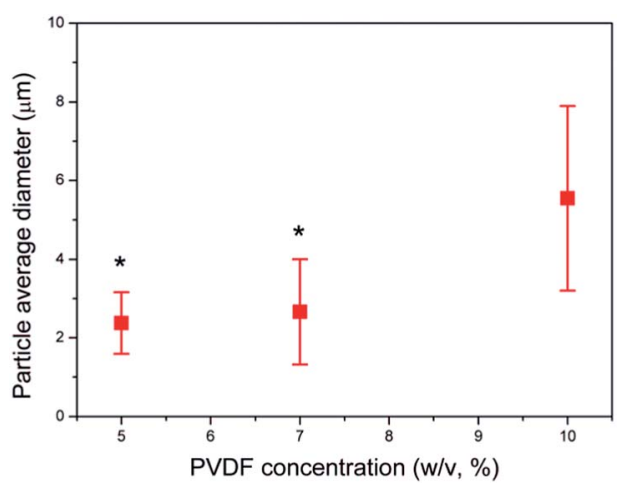

Fig. 2 Influence of the PVDF solution concentration (\% w/v) on microparticle average diameter. The bars in the graph are the standard deviation of the fiber diameter distribution. $* P \leq 0.05$ vs. PVDF concentration of $10(\% \mathrm{w} / \mathrm{v})$. solution overcomes the surface tension of the solution and consequently the amount of polymer sprayed during the electrospray process will increase. In this sense, the effect of the applied electric field in polymer average diameter and microparticle size distribution was evaluated for applied electric fields between 0.75 to $1.25 \mathrm{kV} \mathrm{cm}^{-1}$ (Fig. 3). For larger applied electric fields elongated microparticles or fibers are formed. On the other hand, when lower electric fields are applied to the polymer solution, the main droplet will be maintained more stable, and ejection of smaller jets from the main one will promote PVDF microparticles with larger size distribution (Fig. 3c).

Effect of flow rate on microparticle size. Flow rate will determine the amount of polymer solution available for electrospraying. Moreover, for higher feed rates, solvent total evaporation during the travel from the needle tip to the ground collector is not possible and consequently microparticles are partially solvated when they impact the collector, leading to a deformed and non-consistent morphology. ${ }^{18}$ Fig. 4a shows that flow rate was noticeable determinant in the production of PVDF microparticles. For low flow rates of $0.2 \mathrm{~mL} \mathrm{~h}^{-1}$, microparticles have smaller average diameter, while for higher polymer feed rates microparticles with a higher average diameter was obtained (Fig. 4b), that are independent on the flow rate. These results are explained by the competing mechanism of Coulomb fission and chain entanglements undergoing solvent evaporation. The phenomenon of Coulomb fission, a process by which charge droplet emits a cloud of highly charged small droplets, occurs when a charged drop approach the Rayleigh limit $\left(\varphi_{\text {Ray }}\right)$, the limit value at which the drop cannot hold more charge. For higher polymer solution feed rates $\left(>4 \mathrm{~mL} \mathrm{~h}^{-1}\right)$, it was observed that due to the higher amount of the solution that is drawn from the needle tip, the jet takes more time to dry, and consequently the solvent present in the deposited microparticles has not time enough to evaporate at the same flight time, promoting particle adhesion to each other in the metallic ground collector.

The average size of microparticles for the different needle inner diameters was evaluated (Fig. 4c) and the results show a quite similar microparticle diameter for all the different samples with an average size diameter between 2.0 and $2.5 \mu \mathrm{m}$, being therefore independent of the needle inner diameter.

Fig. 5 summarizes the influence of the polymer concentration on the size of electrosprayed polymer microparticles, as this is the parameter that mainly influences microparticle formation and diameter (Fig. 1). Morphology and size of microparticles can be further tuned by the additional parameters described above in order to obtain fibers without beads and in the case of microparticles the absence of fibers.

Polymer phase content. FTIR spectroscopy is a characterization technique useful for the identification and quantification of the different crystalline phases of PVDF. ${ }^{15,28}$

The chemical structure of PVDF is composed by the repetition unit- $\mathrm{CH}_{2}-\mathrm{CF}_{2}-$ along the polymer chain and characteristic vibrational modes can be used to the identification of the $\alpha$ and $\beta$ phases. ${ }^{15,29}$ The $\alpha$-phase can be identified by the presence of absorption bands at 489, 530, 615 and $766 \mathrm{~cm}^{-1}$ attributed to 

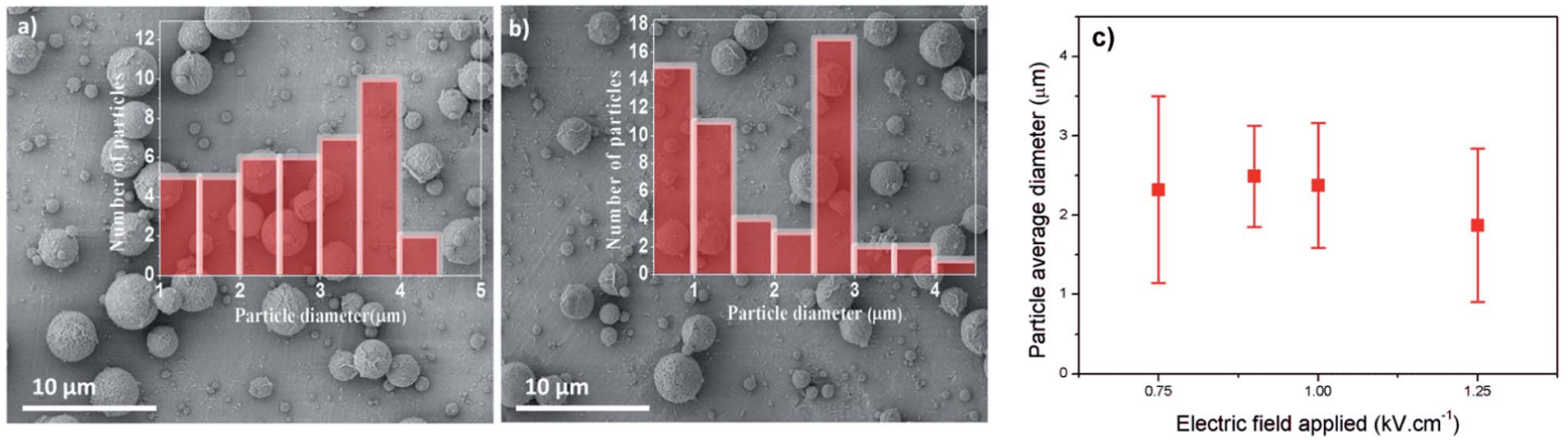

Fig. 3 Morphology of the PVDF microparticles for the samples obtained with a $5(\% \mathrm{w} / \mathrm{v})$ polymer solution at different applied voltages: (a) $E=$ $0.75 \mathrm{kV} \mathrm{cm}^{-1}$ (b) $1.25 \mathrm{kV} \mathrm{cm}^{-1}$ and (c) influence of the applied electrical field $\left(\mathrm{kV} \mathrm{cm}^{-1}\right)$ on the microparticle average diameter. Samples prepared with needle diameter of $0.2 \mathrm{~mm}$, flow rate of $2 \mathrm{~mL} \mathrm{~h}^{-1}$ at a traveling distance of $20 \mathrm{~cm}$. The bars in the graph are the standard deviation of the fiber diameter distribution.
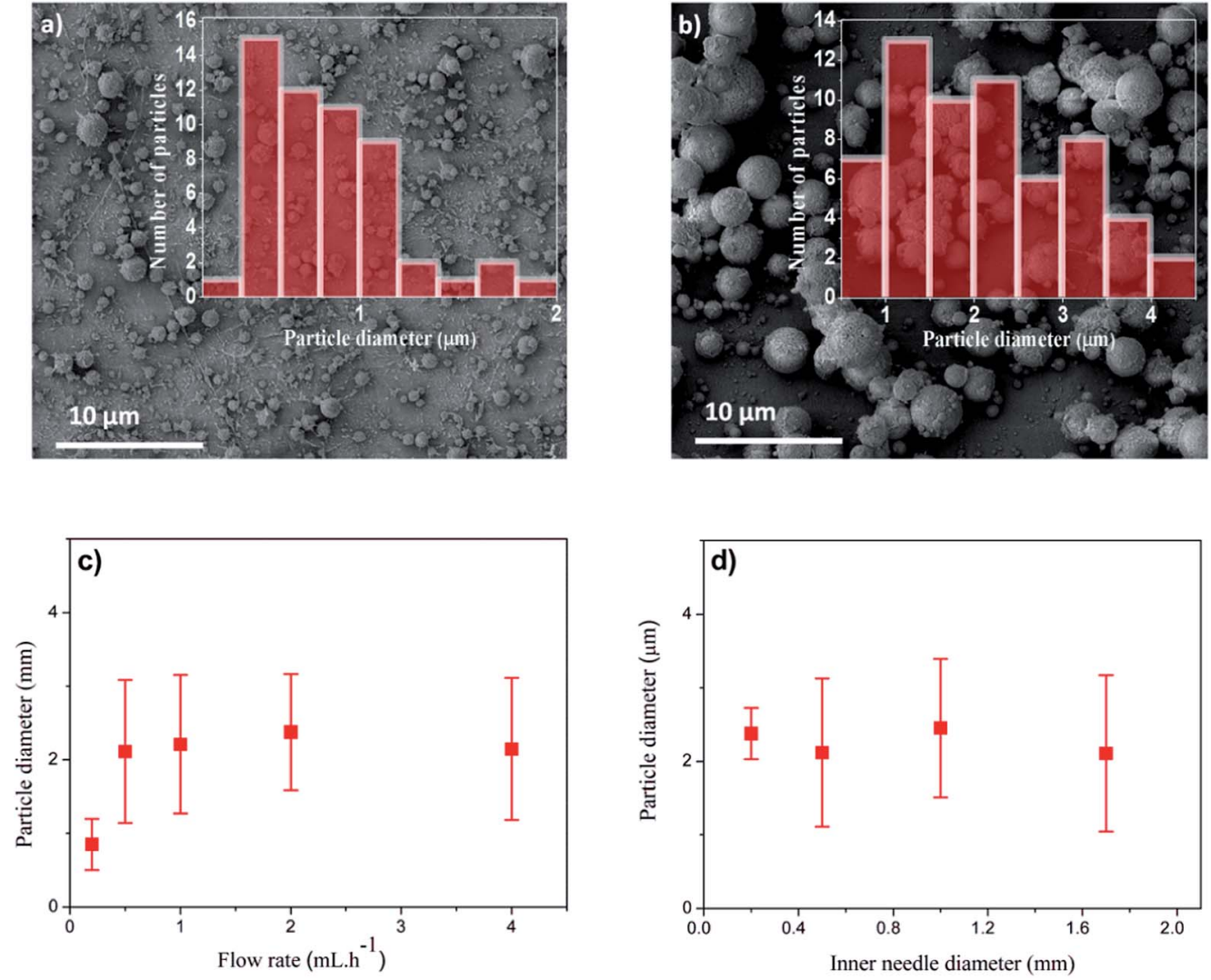

Fig. 4 Morphology of the PVDF microparticles for the samples obtained with a $5(\% \mathrm{w} / \mathrm{v})$ polymer solution at different flow rates (a) $0.2 \mathrm{~mL} \mathrm{~h}^{-1}$ and (b) $4 \mathrm{~mL} \mathrm{~h}^{-1}$ with a needle diameter of $0.2 \mathrm{~mm}$, electric applied field of $20 \mathrm{kV} \mathrm{cm}^{-1}$ at a traveling distance of $20 \mathrm{~cm}$. The microparticle diameter histograms of the corresponding figures are also given in the figure. (c) and (d) Influence of the flow rate ( $\mathrm{mL} \mathrm{h}^{-1}$ ) and inner needle diameter $(\mathrm{mm})$ respectively on the microparticle average diameter. The bars in the graph are the standard deviation of the diameter distribution.

stretching of the group $\mathrm{CF}_{2}$, at $795 \mathrm{~cm}^{-1}$ corresponding to the $\mathrm{CH}_{2}$ stretching and at 855 and $976 \mathrm{~cm}^{-1}$ resulting of the $\mathrm{CH}$ group stretching. ${ }^{30}$ The $\beta$-phase content present in the sample can be determined by the absorption infrared band at $840 \mathrm{~cm}^{-1}$ corresponding to the stretching of the $\mathrm{CH}_{2}$ absorption band and by 511 and $600 \mathrm{~cm}^{-1}$ characteristic of $\mathrm{CF}_{2}$ and $\mathrm{CF}$ stretching, respectively. ${ }^{15,30}$
Fig. 6a shows FTIR-ATR spectrum of representative PVDF electrospray microparticles and $\alpha$-PVDF film for comparison. Electroactive $\beta$-phase is desired for sensor and actuator applications as well as for tissue and biomedical engineering due to its piezoelectric properties that enhances cell growth and proliferation. ${ }^{12,14}$ Fig. 6a shows that the characteristic bands of $\beta$-PVDF and $\alpha$-phase are present in the polymer microparticles. 


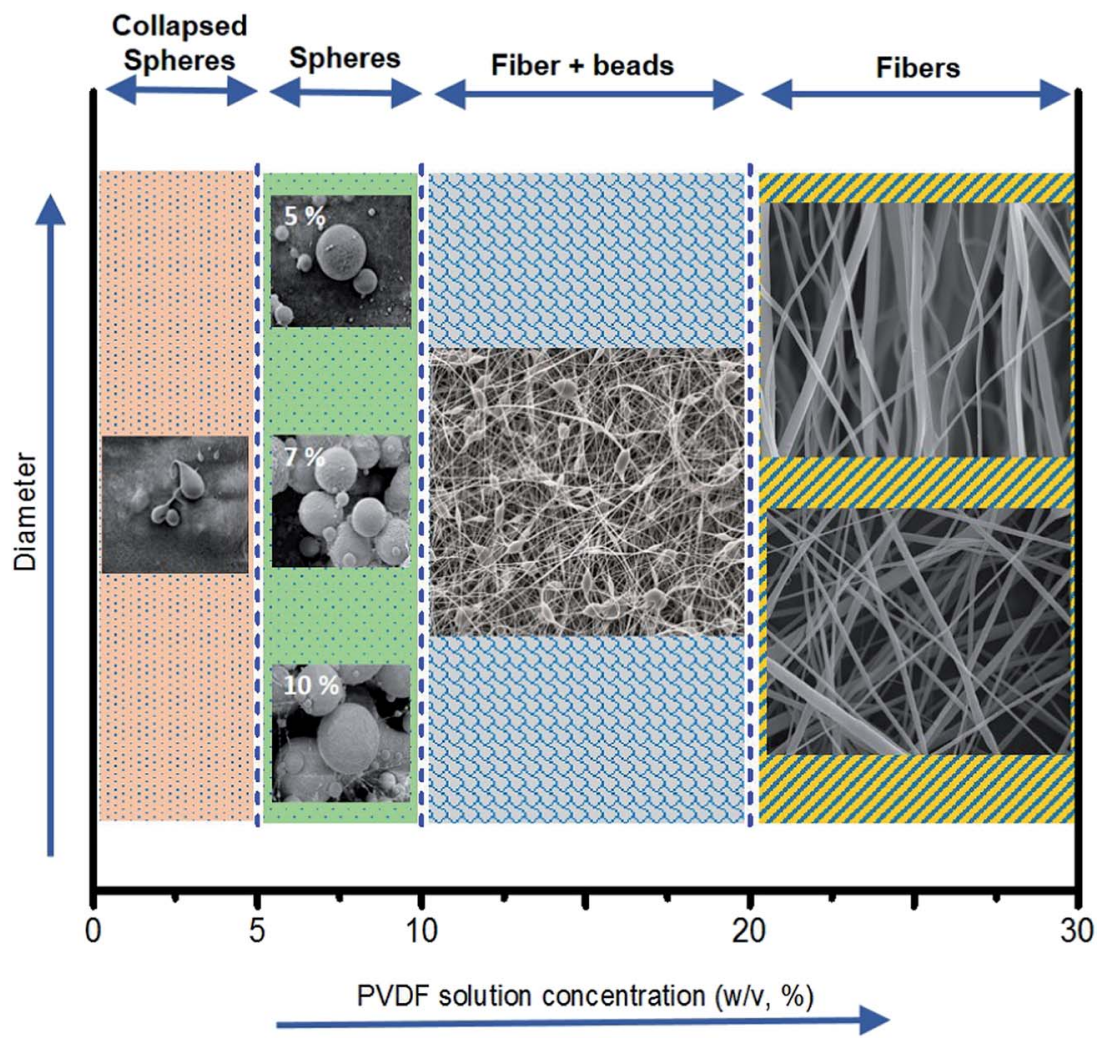

Fig. 5 Schematic diagram of the influence of PVDF solution concentration in the production of microparticles and fibers by electrospray.
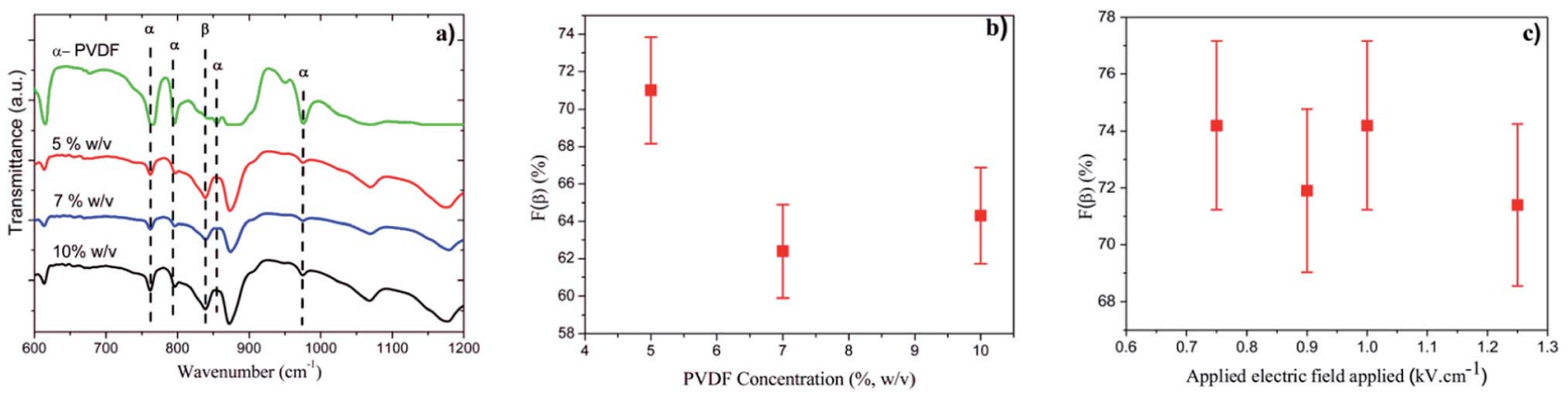

Fig. 6 (a) FTIR spectrums of 5, 7 and 10 (\% w/v) PVDF microparticles and $\alpha$-PVDF film; (b) the variation of $\beta$ phase content with the concentration and (c) with the applied electric field for $5(\% \mathrm{w} / \mathrm{v})$ samples.

This fact has been previously reported for electrospun PVDF fibers and their composites $\mathbf{1 5}^{\mathbf{1 5} \mathbf{2 6}}$ and was attributed to the combination of low solvent evaporation and electric field stretching of the fibers. ${ }^{30}$ It the case of microparticles produced by electrospray the presence of the electroactive phase is due to the low temperature solvent evaporation.

The evolution of the $\beta$-phase content of the microparticles was determined by the eqn (1), as explained elsewere: ${ }^{15,29}$

$$
F(\beta)=\frac{A_{\beta}}{\left(\frac{K_{\beta}}{K_{\alpha}}\right) A_{\alpha}+A_{\beta}}
$$

where $F(\beta)$ represents the $\beta$-phase content, $K_{\alpha}$ and $K_{\beta}$ the absorption coefficient for each phase and $A_{\alpha}$ and $A_{\beta}$ the absorbance at 766 and $840 \mathrm{~cm}^{-1}$, respectively. The absorption coefficient value is $7.7 \times 10^{4} \mathrm{~cm}^{2} \mathrm{~mol}^{-1}$ and $6.1 \times 10^{4} \mathrm{~cm}^{2} \mathrm{~mol}^{-1}$ for $K_{\beta}$ and $K_{\alpha}$, respectively. ${ }^{15,31}$ The variation of $\beta$-phase content with polymer concentration and applied electric field is present in Fig. $6 \mathrm{~b}$ and $\mathrm{c}$.

Fig. $6 \mathrm{~b}$ and $\mathrm{c}$ shows that electrospray processing parameters does not influence substantially the amount of $\beta$-phase content present in the sample as phase content is mainly determined by the low crystallization temperature (room temperature) that favors polymer crystallization in the electroactive phase. ${ }^{28}$ 
Thermal characterization. Differential scanning calorimetry (DSC) has been often used in the identification and in the quantification of the PVDF crystalline phases. ${ }^{15,28}$ The characteristic melting peaks depends both on crystalline phase and morphology of the polymeric structure.$^{15}$ It is thus stated that the melting temperature of the $\alpha$ and $\beta$ PVDF occurs in the range of $167^{\circ} \mathrm{C}$ to $172{ }^{\circ} \mathrm{C} .{ }^{15} \mathrm{Fig}$. $7 \mathrm{a}$ and b show the characteristic DSC thermographs of the microparticles, showing single melting peaks with a melting temperature $\left(T_{\mathrm{m}}\right)$ of $170{ }^{\circ} \mathrm{C}$ for the samples prepared for 5, 7 and $10(\% \mathrm{w} / \mathrm{v})$ solution concentrations and for microparticles obtained at different applied electric fields. The degree of crystallinity $\left(X_{\mathrm{c}}\right)$ of the samples was determined from the DSC curves using eqn (2): ${ }^{\mathbf{6}}$

$$
X_{\mathrm{c}}=\frac{\Delta H}{x \Delta H_{\alpha}+y \Delta H_{\beta}}
$$

where $\Delta H$ is the melting enthalpy of the sample; $\Delta H_{\alpha}$ and $\Delta H_{\beta}$ are the melting enthalpies of a $100 \%$ crystalline sample in the $\alpha$ and $\beta$ phase and the $x$ and $y$ the amount of the $\alpha$ and $\beta$ phase present in the sample, respectively. ${ }^{26} 93.07 \mathrm{~J} \mathrm{~g}^{-1}$ and $103.4 \mathrm{~J} \mathrm{~g}^{-1}$ were used for $\Delta H_{\alpha}$ and $\Delta H_{\beta}$, respectively. ${ }^{26}$ It was observed that processing parameters led to variation in the degree of crystallinity between 47 and 57\%, the melting temperature being independent on the processing conditions (Fig. 7c and d). These results are similar to the ones observed for electrospun PVDF fiber mats. ${ }^{26}$
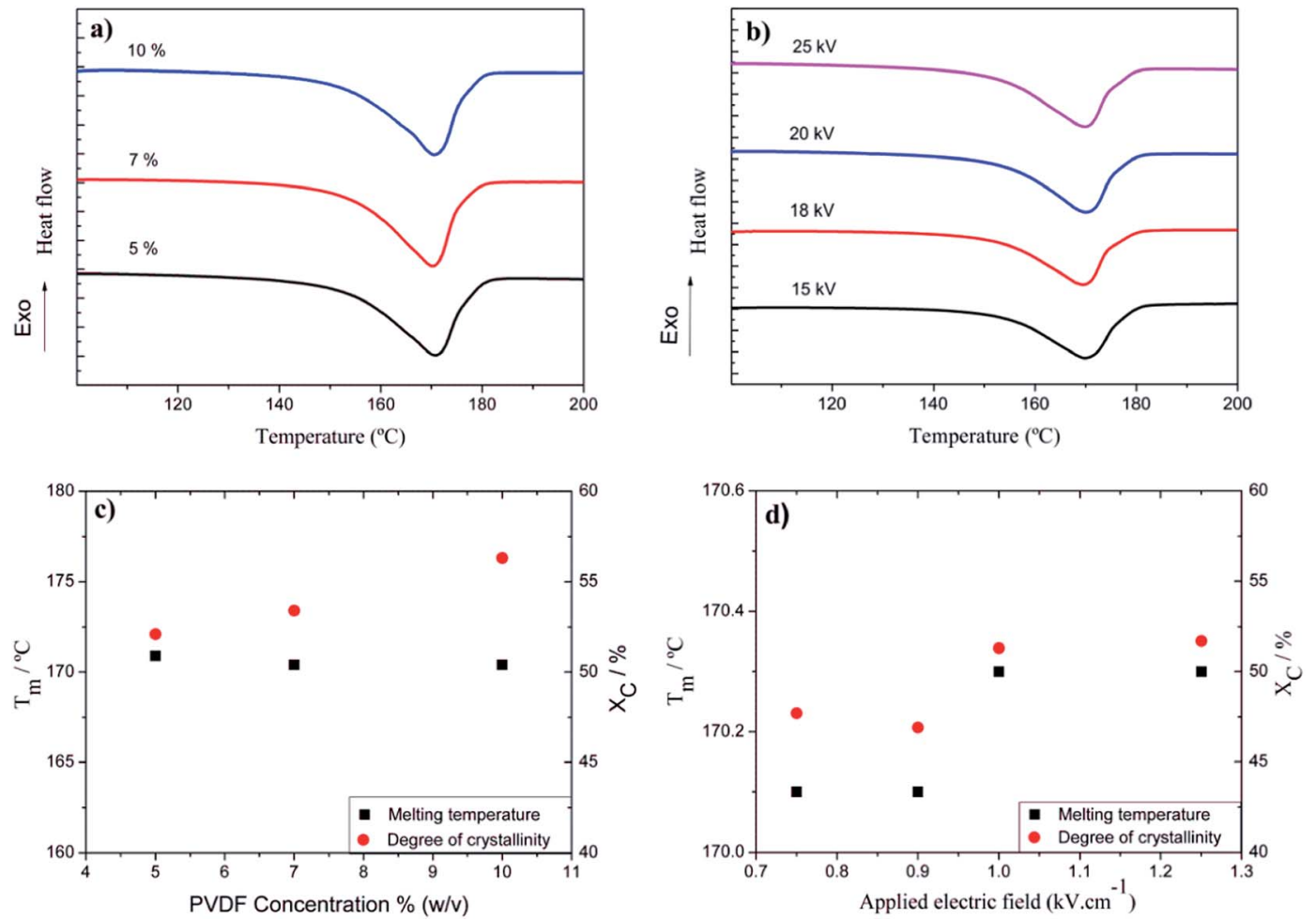

Fig. 7 DSC thermographs of the PVDF microparticles obtained from (a) 5, 7 and 10 (\% w/v) polymer solutions and (b) at different applied electric fields. Variation of the sample melting temperature and degree of crystallinity with (c) the solution concentration and (d) applied electric field, respectively.

a)

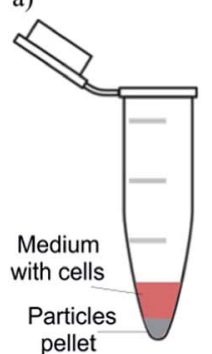

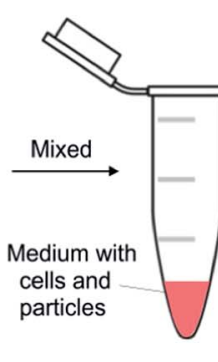

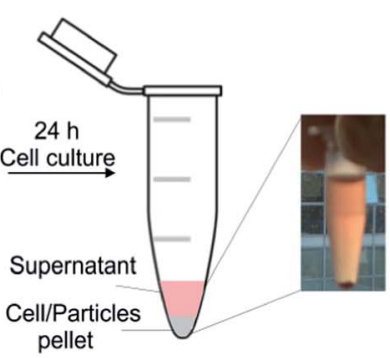

b)

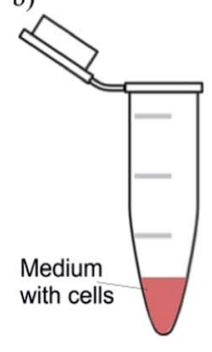

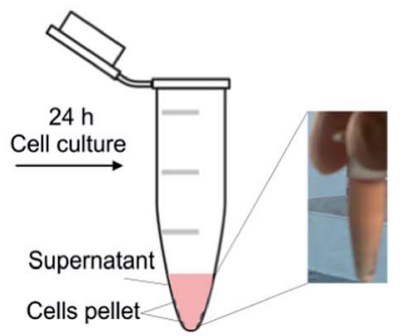

Fig. 8 Schematic representation and pictures of MC3T3-E1 cells with and without PVDF microparticles cultured in vitro after $24 \mathrm{~h}$ incubation: (a) MC3T3-E1 cells mixed with microparticles; (b) cells without microparticles used as control. 


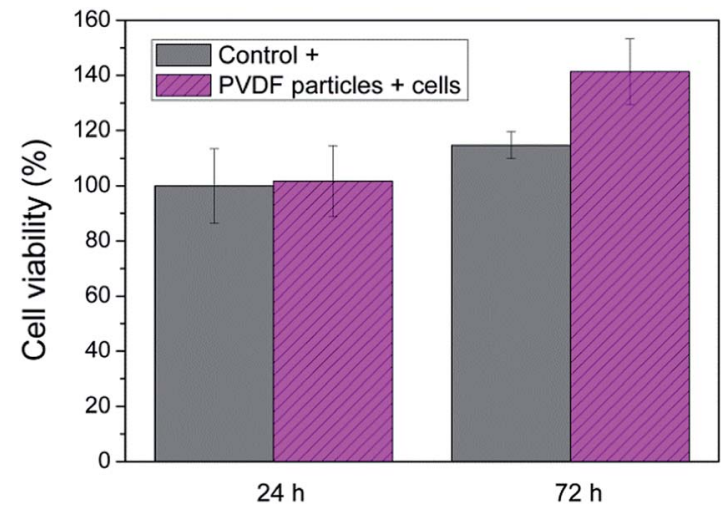

Fig. 9 Cell viability for PVDF microparticles/cells and cells pellets $($ control + ). Results are expressed as mean \pm standard deviation with $n=3$.

\section{Cell viability}

Fig. 8 shows the schematic representation and pictures of MC3T3-E1 cells with and without PVDF microparticles cultured in vitro after $24 \mathrm{~h}$ incubation. It is observed that, after $24 \mathrm{~h}$, PVDF microparticles mixed with MC3T3-E1 pre-osteoblast formed a cell/microparticles pellet in the bottom of the Eppendorf (Fig. 8(a)). On the other hand, the positive control does not form a stable structure and the cells remain dispersed in the Eppendorf or forming small aggregates at the walls of the Eppendorf.

The viability of MC3T3-E1 cells seeded in an Eppendorf with and without PVDF microparticles was examined by MTT assay (Fig. 9). The obtained results reveal that the cell agglomerates are viable for both. Comparing the PVDF microparticles/cells pellet with the cell pellet used as control it is possible to verify a higher number of cells after $72 \mathrm{~h}$ on the pellet with microparticles. This result shows that the PVDF microparticles can provide a suitable environment for cell growth, than can be further explored through suitable mechanical stimulation leading to electromechanical response of the microparticles. ${ }^{\mathbf{1 4}}$

\section{Conclusions}

PVDF microparticles have been prepared by a stable electrospray process from a PVDF solution concentration using DMFTHF. It was observed that dilute or semi dilute concentrations favored the formation of PVDF microparticles, with average diameters ranging between $0.81 \pm 0.34$ and $5.55 \pm 2.34 \mu \mathrm{m}$ for concentrations between 2 and 7\% respectively, while higher concentration promotes fibers formation. No significant differences occur in the average microparticle diameter with the variation of the electrospray processing parameters.

Infrared spectroscopy showed that electrospray allows the processing of the PVDF microparticles in the $\beta$-phase, with electroactive phase contents of around $70 \%$. Moreover, processing parameters does not influence substantially the amount of $\beta$-phase content.
DSC results of the PVDF microparticles show that the cosolvents used during the PVDF dissolution and the varying electrospray processing conditions allow variations in the degree of crystallinity between 47 and 57\%, being the melting temperature of the samples independent on the processing conditions.

MC-3T3-E1 cell adhesion was not inhibited by the PVDF microparticles preparation, indicating the suitability of the material for the development of electroactive scaffold for biomedical applications.

\section{Acknowledgements}

This work is funded by FEDER funds through the "Programa Operacional Fatores de Competitividade - COMPETE" and by national funds arranged by FCT-Fundação para a Ciência e a Tecnologia, project references NANO/NMed-SD/0156/2007, PTDC/CTM-NAN/112574/2009, PEST-C/FIS/UI607/2011 and PEST-C/QUI/UIO686/2013. The authors also thank funding from Matepro - Optimizing Materials and Processes", ref. NORTE-07-0124-FEDER-000037", co-funded by the "Programa Operacional Regional do Norte" (ON.2 - O Novo Norte), under the "Quadro de Referência Estratégico Nacional" (QREN), through the "Fundo Europeu de Desenvolvimento Regional" (FEDER). The authors also thank support from the COST Action MP1003, 2010 'European Scientific Network for Artificial Muscles', MP1206 "Electrospun Nano-fibres for bio inspired composite materials and innovative industrial applications" and MP1301 "New Generation Biomimetic and Customized Implants for Bone Engineering”. DMC, RG, CR and VS thank the FCT for the SFRH/BD/82411/2011, SFRH/BD/90215/2012, SFRH/ $\mathrm{BPD} / 90870 / 2012$ and SFRH/BPD/64958/2009 grants, respectively. The authors also thank R. Machado e M. Casal do 3CBMA, (Centre of Molecular and Environmental Biology), Department of Biology, University of Minho, Campus de Gualtar, 4710-057 Braga, Portugal for useful discussions and allowing the use of specific equipment. CIBER-BBN is an initiative funded by the VI National R\&D\&i Plan 2008-2011, Iniciativa Ingenio 2010, Consolider Program, CIBER Actions and financed by the Instituto de Salud Carlos III with assistance from the European Regional Development Fund and Ministerio de Economía y Competitividad, MINECO, through the MAT201346467-C4-1-R project.

\section{Notes and references}

1 M. B. Oliveira and J. F. Mano, Biotechnol. Prog., 2011, 27, 897912.

2 Q. Chen, S. Liang and G. A. Thouas, Prog. Polym. Sci., 2013, 38, 584-671.

3 A. Seidi, M. Ramalingam, I. Elloumi-Hannachi, S. Ostrovidov and A. Khademhosseini, Acta Biomater., 2011, 7, 1441-1451.

4 Y. Tabata, Drug Discovery Today, 2005, 10, 1639-1646.

5 M. Bhamidipati, B. Sridharan, A. M. Scurto and M. S. Detamore, Mater. Sci. Eng., C, 2013, 33, 4892-4899.

6 N. Bock, M. A. Woodruff, D. W. Hutmacher and T. R. Dargaville, Polymers, 2011, 3, 131-149. 
7 S. J. Hong, H. S. Yu and H. W. Kim, Acta Biomater., 2009, 5, 1725-1731.

8 H.-F. Guo, Z.-S. Li, S.-W. Dong, W.-J. Chen, L. Deng, Y.-F. Wang and D.-J. Ying, Colloids Surf., B, 2012, 96, 29-36.

9 N. Weber, Y. S. Lee, S. Shanmugasundaram, M. Jaffe and T. L. Arinzeh, Acta Biomater., 2010, 6, 3550-3556.

10 M. E. Furth, A. Atala and M. E. Van Dyke, Biomaterials, 2007, 28, 5068-5073.

11 C. Ribeiro, J. A. Panadero, V. Sencadas, S. Lanceros-Mendez, M. N. Tamano, D. Moratal, M. Salmeron-Sanchez and J. L. Gomez Ribelles, Biomed. Mater., 2012, 7, 035004.

12 P. M. Martins, S. Ribeiro, C. Ribeiro, V. Sencadas, A. C. Gomes, F. M. Gama and S. Lanceros-Mendez, RSC Adv., 2013, 3, 17938-17944.

13 H. Lee and B. Bhushan, J. Colloid Interface Sci., 2011, 360, 777-784.

14 C. Ribeiro, S. Moreira, V. Correia, V. Sencadas, J. G. Rocha, F. M. Gama, J. L. Gomez Ribelles and S. Lanceros-Mendez, RSC Adv., 2012, 2, 11504-11509.

15 P. Martins, A. C. Lopes and S. Lanceros-Mendez, Prog. Polym. Sci., 2013, 39, 683-706.

16 M. Zamani, M. P. Prabhakaran and S. Ramakrishna, Int. J. Nanomed., 2013, 8, 2997-3017.

17 I. B. Rietveld, K. Kobayashi, H. Yamada and K. Matsushige, J. Colloid Interface Sci., 2006, 298, 639-651.

18 N. Bock, T. R. Dargaville and M. A. Woodruff, Prog. Polym. Sci., 2012, 37, 1510-1551.

19 D. M. García Cruz, V. Sardinha, J. L. Escobar Ivirico, J. F. Mano and J. L. Gómez Ribelles, J. Mater. Sci.: Mater. Med., 2013, 24, 503-513.
20 N. Garcia-Giralt, D. M. Garcia Cruz, X. Nogues, J. L. E. Ivirico and J. L. G. Ribelles, RSC Adv., 2013, 3, 6362-6368.

21 S. D. Nath, S. Son, A. Sadiasa, Y. K. Min and B. T. Lee, Int. J. Pharm., 2013, 443, 87-94.

22 J. M. Deitzel, J. Kleinmeyer, D. Harris and N. C. Beck Tan, Polymer, 2001, 42, 261-272.

23 M. Nasir, H. Matsumoto, T. Danno, M. Minagawa, T. Irisawa, M. Shioya and A. Tanioka, J. Polym. Sci., Part B: Polym. Phys., 2006, 44, 779-786.

24 C. L. Casper, J. S. Stephens, N. G. Tassi, D. B. Chase and J. F. Rabolt, Macromolecules, 2003, 37, 573-578.

25 W. Rungswang, M. Kotaki, T. Shimojima, G. Kimura, S. Sakurai and S. Chirachanchai, Polymer, 2011, 52, 844-853.

26 C. Ribeiro, V. Sencadas, J. L. G. Ribelles and S. LancerosMéndez, Soft Mater., 2010, 8, 274-287.

27 L. M. M. Costa, R. E. S. Bretas and R. Gregorio, Jr., Mater. Sci. Appl., 2010, 1, 247-252.

28 V. Sencadas, R. Gregorio and S. Lanceros-Méndez, J. Macromol. Sci., Part B: Phys., 2009, 48, 514-525.

29 Y. Bormashenko, R. Pogreb, O. Stanevsky and E. Bormashenko, Polym. Test., 2004, 23, 791-796.

30 A. Lopes, C. Ribeiro, V. Sencadas, G. Botelho and S. Lanceros-Méndez, J. Mater. Sci., 2014, 49, 3361-3370.

31 R. Gonçalves, P. M. Martins, C. Caparrós, P. Martins, M. Benelmekki, G. Botelho, S. Lanceros-Mendez, A. Lasheras, J. Gutiérrez and J. M. Barandiarán, J. NonCryst. Solids, 2013, 361, 93-99. 